\title{
Nuclear Aurora B and cytoplasmic Survivin expression is involved in lymph node metastasis of colorectal cancer
}

\author{
HANDAN TUNCEL ${ }^{1}$, FUMIO SHIMAMOTO ${ }^{2}$, HIROSHI KANEKO (GUANGYING QI) ${ }^{2}$, ERIKO AOKI ${ }^{2}$, \\ HIROSHI JIKIHARA ${ }^{2}$, SHIRO NAKAI $^{3}$, TAKASHI TAKATA $^{4}$ and MASAAKI TATSUKA ${ }^{5}$ \\ ${ }^{1}$ Department of Biophysics, Cerrahpasa Medical Faculty, Istanbul University, Fatih, Istanbul 34303, Turkey; \\ ${ }^{2}$ Department of Health Sciences, Faculty of Human Culture and Science, Prefectural University of Hiroshima, Minami-ku, \\ Hiroshima 734-8558; ${ }^{3}$ Department of Surgery, Hiroshima Memorial Hospital, Naka-ku, Hiroshima 730-0802; \\ ${ }^{4}$ Department of Oral and Maxillofacial Pathobiology, Division of Frontier Medical Science, Hiroshima University, \\ Graduate School, Minami-ku, Hiroshima 734-8553; ${ }^{5}$ Department of Life Science, Faculty of Life Environmental Science, \\ Prefectural University of Hiroshima, Shobara, Hiroshima 727-0023, Japan
}

Received December 22, 2011; Accepted February 22, 2012

DOI: $10.3892 / \mathrm{ol} .2012 .633$

\begin{abstract}
The chromosomal passenger complex (CPC) is a key regulator of chromosome segregation and cytokinesis, and consists of Aurora B kinase, INCENP, Survivin and Borealin. Aurora B is a member of a family of serine/threonine protein kinases, and Survivin belongs to the inhibitors of apoptosis (IAP) gene family, and is also a member of the CPC family. Aurora B and Survivin have also been reported to be overexpressed in various human cancers; however, as yet no studies have investigated the co-expression of Survivin and Aurora B in colorectal carcinoma. Therefore, in the present study, the correlation between Aurora B and Survivin expression was investigated using immunohistochemistry and the associated pathological features in colorectal carcinoma were analyzed. Our present findings showed that nuclear Aurora B and cytoplasmic Survivin expression are strongly associated with and involved in lymph node metastasis in colorectal cancer. Therefore, we suggest that nuclear Aurora B and cytoplasmic Survivin are useful diagnostic markers and therapeutic targets in colorectal carcinoma.
\end{abstract}

\section{Introduction}

Aurora B is a member of a family of serine/threonine protein kinases and phosphorylates a variety of substrate proteins, including histone $\mathrm{H} 3$ at ser10, to regulate numerous aspects of

Correspondence to: Dr Fumio Shimamoto, Department of Health Sciences, Faculty of Human Culture and Science, Prefectural University of Hiroshima, 1-1-71 Ujina-Higashi, Minami-ku, Hiroshima 734 8558, Japan

E-mail: simamoto@pu-hiroshima.ac.jp

Key words: Aurora B, Survivin, colorectal carcinoma, lymph node metastasis cell division, from chromosome condensation to cytokinesis $(1,2)$. It is also a protein of the chromosomal passenger complex (CPC), localized on the centromeres from the prophase through to the metaphase-anaphase transition together with Survivin, inner centromere protein (INCENP) and Borealin to regulate segregation and cytokinesis (1-5). Aurora B is overexpressed in a various types of cancer including thyroid, prostate and endometrial carcinomas, and its upregulation is associated with cell proliferation, prognosis, metastasis and chromosomal number instability to produce multinuclearity (2-5). Previously, we also found that nuclear Aurora B expression is correlated with cell proliferation, multinuclearity and metastasis in oral cancer (6). However, the expression of Aurora B in colorectal cancer tissues is undetermined.

Survivin is a 142 amino acid protein containing a baculovirus inhibitor of apoptosis repeat protein domain, and thus is involved in inhibiting apoptosis $(7,8)$. Additionally, it appears to function as a subunit of CPC to regulate cell division (1). Survivin is reported to be overexpressed in a variety of human cancers (7). At present, however, no studies that have investigated the co-expression of Survivin and Aurora B in colorectal carcinoma are available.

Therefore, the aim of this study was to investigate the correlation between Aurora B and Survivin expression and associated pathological features in colorectal carcinoma.

\section{Materials and methods}

Patients. Sixty-five patients who had undergone surgical resection for advanced colorectal carcinoma at Hiroshima Memorial Hospital, Japan, were enrolled in this study. In addition, 20 samples of normal colonic mucosa were examined as controls. Tumors from each patient were formalin-fixed and cut into parallel 4-5 $\mathrm{mm}$ sections, and the site of deepest tumor invasion was selected by microscopic examination in combination with hematoxylin and eosin staining. The study was approved by the ethics committee of the Hiroshima Memorial Hospital. Informed consent was obtained from all subjects. 
Table I. Aurora B and Survivin expression in normal colonic mucosa and colorectal cancer.

\begin{tabular}{|c|c|c|c|}
\hline & Normal (\%) & Cancer $(\%)$ & P-value \\
\hline Number of cases & 20 & 65 & \\
\hline \multicolumn{4}{|l|}{ Aurora B } \\
\hline $\mathrm{N}+$ & $0(0)$ & $38(58.5)$ & $<0.01$ \\
\hline $\mathrm{N}-$ & $20(100)$ & $27(41.5)$ & \\
\hline \multicolumn{4}{|l|}{ Survivin } \\
\hline $\mathrm{N}+$ & $0(0)$ & $48(73.8)$ & $<0.01$ \\
\hline $\mathrm{N}-$ & $20(100)$ & $17(16.2)$ & \\
\hline \multicolumn{4}{|l|}{ Survivin } \\
\hline $\mathrm{C}+$ & $0(0)$ & $27(41.5)$ & $<0.01$ \\
\hline $\mathrm{C}-$ & $20(100)$ & $38(58.5)$ & \\
\hline
\end{tabular}

$\mathrm{N}+$, positive nuclear expression; $\mathrm{N}-$, negative nuclear expression; $\mathrm{C}+$, positive cytoplasmic expression; $\mathrm{C}$-, negative cytoplasmic expression.

Immunohistochemical staining. Immunohistochemical staining for Aurora B and Survivin was performed with the LSAB system (Dako, Kyoto, Japan). In brief, paraffin blocks were cut into 3-4 $\mu \mathrm{m}$ sections. The sections were deparaffinized in xylene for $2 \mathrm{~h}$, dehydrated with graded ethanol washes (100-70\%) and treated with $3 \%$ hydrogen peroxide for $30 \mathrm{~min}$. The sections were autoclaved three times in $10 \mathrm{mM}$ citrate buffer ( $\mathrm{pH}$ 6.0) for 5 min to allow antigen retrieval, and incubated overnight in anti-Aurora B primary monoclonal antibody (Transduction Laboratories, San Diego, CA, USA; 1:50 dilution) and anti-Survivin polyclonal antibody (NB500-201, Novus Biological, Littleton, CO, USA; 1:1000 dilution) at $4^{\circ} \mathrm{C}$. Aurora B and Survivin expression was semi-quantitatively estimated by determining nuclear and cytoplasmic localization. Immunoreactivity was graded according to the percentage of positive tumor cells, as follows: +++ , strong $(>60 \%$ of the tumor cells intensely stained); ++ , moderate (20-60\% intensely stained); + , mild ( $<20 \%$ intensely or weakly stained); or - , no staining. Survivin- and Aurora B-positive cases were graded ++ or +++ , and negative cases were graded - or + .

Statistical analysis. The Statcel software package was used to statistically analyze the correlation between pathological factors, including lymph node metastasis, lymphatic invasion, venous invasion and distant metastasis, and the expression of Aurora B and Survivin in colorectal carcinomas. The $\chi^{2}$ or Fisher's exact test were used for comparison of data between the groups. $\mathrm{P}<0.05$ was considered to indicate a statistically significant difference.

\section{Results}

Aurora $B$ and Survivin expression in normal colonic mucosa and colorectal carcinoma. We examined the expression of Aurora B and Survivin in 20 normal colonic mucosa and 65 colorectal carcinoma samples by immunohistochemistry. In normal colonic mucosa, cells exhibited extremely weak staining of Aurora B and Survivin (Fig. 1A-a and c, and Table I). Nuclear Aurora B and nuclear and/or cytoplasmic Survivin exhibited strong staining in colorectal carcinoma (Fig. 1A-b and d, and Table I). All cases showed a low nuclear Aurora B expression, and low nuclear and cytoplasmic Survivin in normal colonic mucosa. Although 38 of 65 cases $(58.5 \%)$ showed nuclear

Table II. Correlation between the expression of Aurora B and Survivin and pathological factors in colorectal cancer.

\begin{tabular}{|c|c|c|c|c|c|c|c|c|c|}
\hline & \multicolumn{2}{|c|}{ Aur B N } & \multirow{2}{*}{ P-value } & \multicolumn{2}{|c|}{ Sur N } & \multirow{2}{*}{ P-value } & \multicolumn{2}{|c|}{ Sur C } & \multirow{2}{*}{ P-value } \\
\hline & + & - & & + & - & & + & - & \\
\hline Number of cases & 38 & 27 & & 48 & 17 & & 27 & 38 & \\
\hline \multicolumn{10}{|c|}{ Pathological features } \\
\hline \multicolumn{10}{|c|}{ Histological differentiation } \\
\hline Well/moderate & 31 & 25 & 0.097 & 41 & 15 & n.s. & 22 & 34 & n.s. \\
\hline Poor/mucinous & 7 & 2 & & 7 & 2 & & 5 & 4 & \\
\hline \multicolumn{10}{|c|}{ Lymph node metastasis } \\
\hline Negative & 23 & 24 & $<0.01$ & 32 & 15 & n.s. & 13 & 34 & $<0.01$ \\
\hline Positive & 15 & 3 & & 12 & 6 & & 14 & 4 & \\
\hline \multicolumn{10}{|c|}{ Lymphatic invasion } \\
\hline Negative & 1 & 0 & n.s. & 1 & 0 & n.s. & 0 & 1 & n.s. \\
\hline Positive & 37 & 27 & & 47 & 17 & & 27 & 37 & \\
\hline \multicolumn{10}{|l|}{ Venous invasion } \\
\hline Negative & 1 & 0 & n.s. & 0 & 1 & n.s. & 1 & 0 & n.s. \\
\hline Positive & 37 & 27 & & 48 & 16 & & 26 & 38 & \\
\hline
\end{tabular}

Sur C, Survivin cytoplasmic expression; Sur N, Survivin nuclear expression; Aur B N, Aurora B nuclear expression; n.s., not significant. 
A
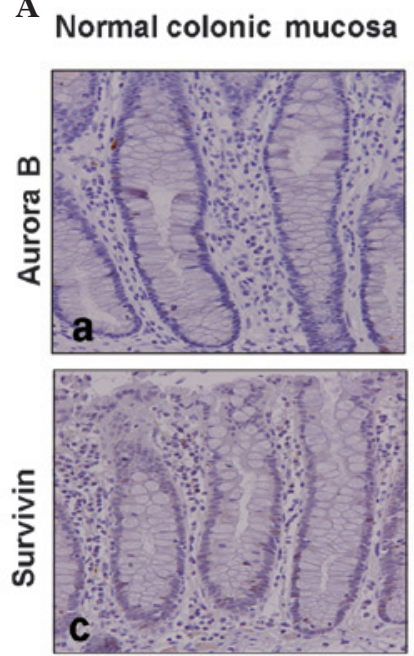
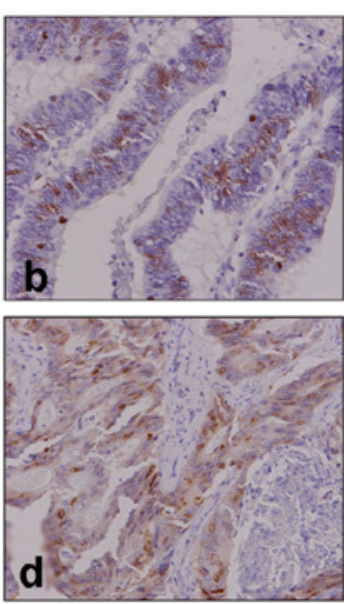

B

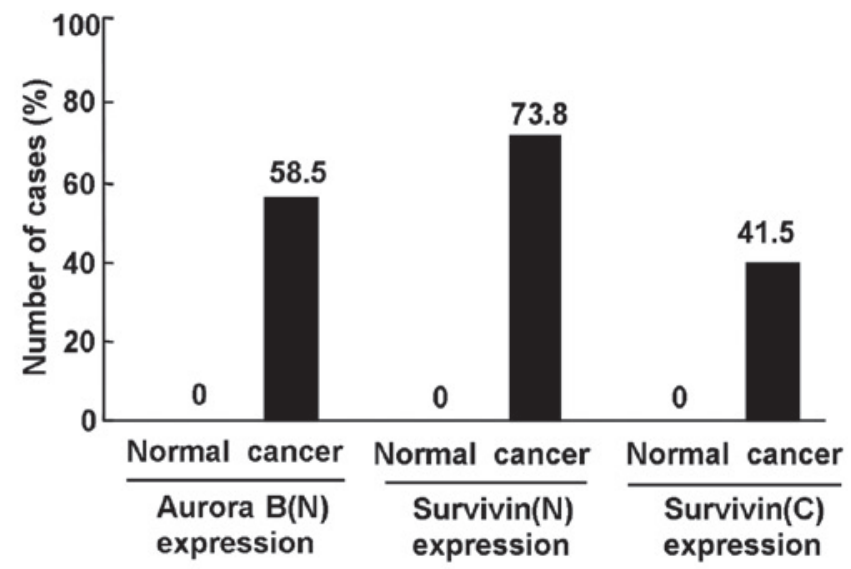

C
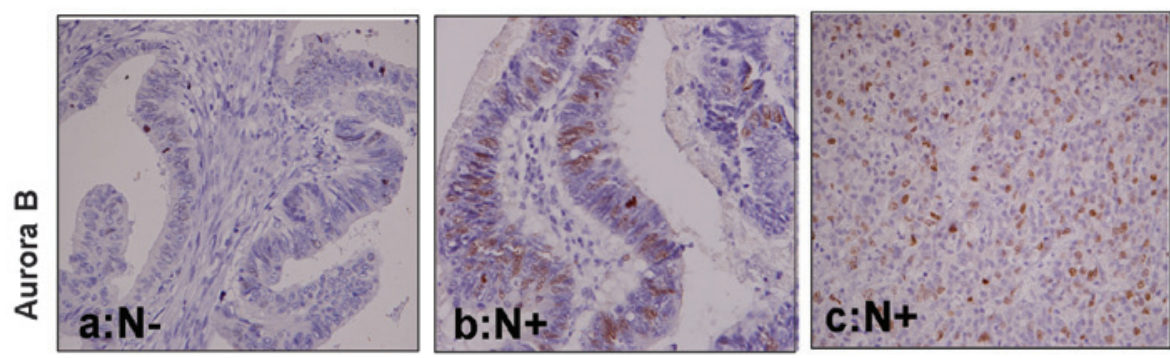

Metastatic lymph nodes
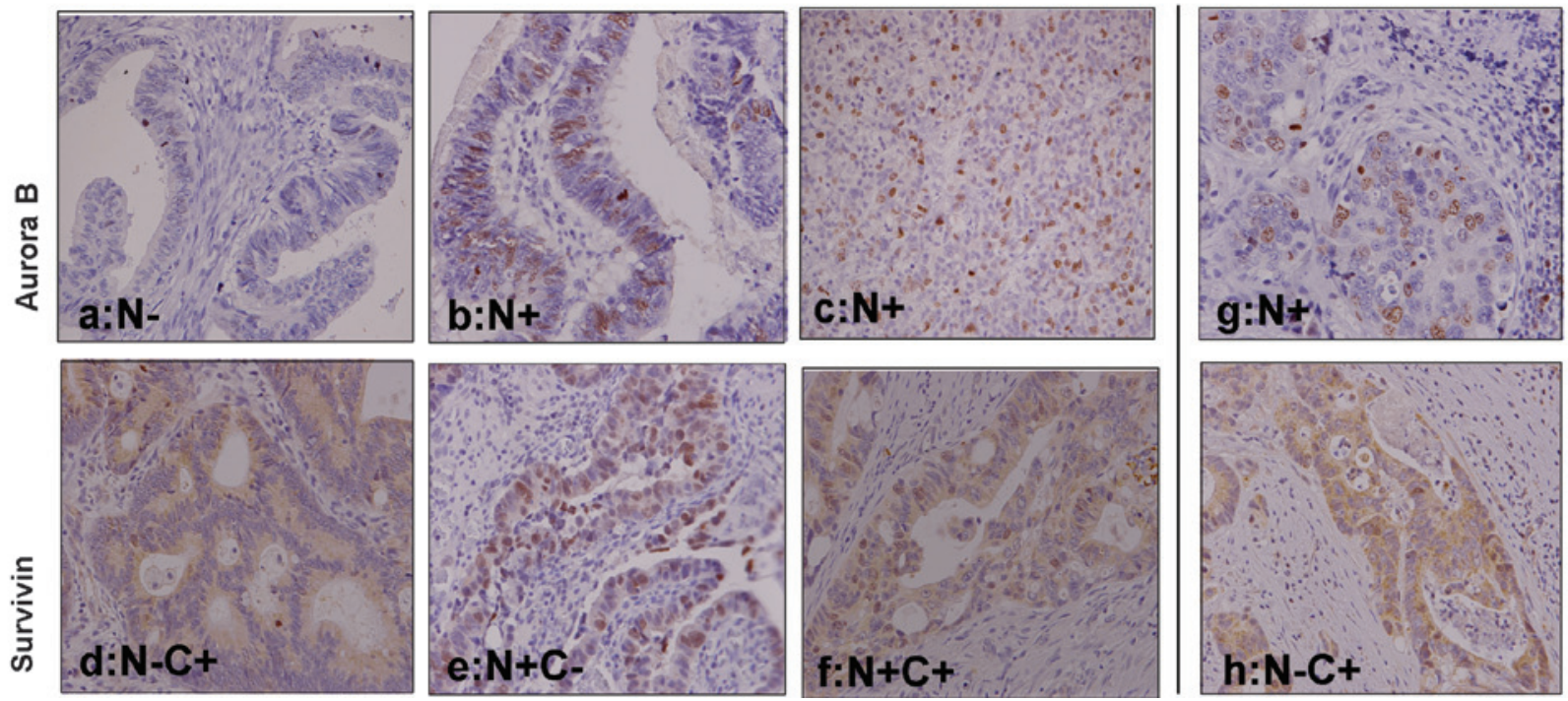

Figure 1. (A) In normal colonic mucosa, cells only exhibited very weak staining for Aurora B (a) and Survivin (c). Nuclear Aurora B (b), and nuclear and cytoplasmic Survivin (d) expression exhibited strong staining in colorectal carcinoma. (B) All cases demonstrated a low expression ( $0 \%$ ) of nuclear Aurora B and nuclear and cytoplasmic Survivin in normal colonic mucosa, while 58.5\% of cases demonstrated nuclear staining of Aurora B, 73.8\% demonstrated exclusive nuclear staining of Survivin and 41.5\% demonstrated cytoplasmic staining. (C) Expression of Aurora B and Survivin in primary colorectal carcinoma or metastatic lymph nodes by immunohistochemistry. Representative cases of low nuclear Aurora B expression (N-) (a) and high nuclear Aurora B expression (N+) (b and c), low nuclear Survivin expression and high cytoplasmic Survivin expression ( $\mathrm{N}-\mathrm{C}+)$ (d), high nuclear Survivin expression and low cytoplasmic Survivin expression (N+C-) (e), and high nuclear and cytoplasmic Survivin expression $(\mathrm{N}+\mathrm{C}+)$ (f) in primary colorectal carcinoma. Representative cases of high nuclear Aurora B expression $(\mathrm{N}+)(\mathrm{g})$ and low nuclear Survivin expression and high cytoplasmic Survivin expression $(\mathrm{N}-\mathrm{C}+)(\mathrm{h})$ are shown.

staining of Aurora B, 48 of 65 cases (73.8\%) showed exclusive nuclear staining of Survivin, and 27 of 65 cases (41.5\%) showed cytoplasmic staining (Fig. 1B and C, and Table I).

Correlation between Aurora B and Survivin expression and pathological factors in colorectal cancer. We examined the correlation between pathological factors and Aurora B and/or Survivin expression in colorectal carcinoma. Aurora B nuclearpositive cases exhibited significantly increased lymph node metastasis $(\mathrm{P}<0.01)$, compared with Aurora B nuclear-negative cases. Survivin cytoplasmic-positive cases also demonstrated significantly increased lymph node metastasis $(\mathrm{P}<0.01)$ compared with Survivin cytoplasmic-negative cases, but Survivin nuclear-positive cases were not significantly different compared with negative cases. Nuclear Aurora B and cytoplasmic Survivin expression were significant factors of poor prognosis (Table II).

The correlation between nuclear Aurora B and cytoplasmic Survivin expression and pathological factors in colorectal carcinomas was examined. Notably, positive cytoplasmic Survivin 
Table III. Correlation between the expression of nuclear Aurora B and cytoplasmic Survivin and pathological factors.

\begin{tabular}{|c|c|c|c|c|c|}
\hline & $\mathrm{N}+\mathrm{C}+$ & $\mathrm{N}+\mathrm{C}-$ & $\mathrm{N}-\mathrm{C}+$ & $\mathrm{N}-\mathrm{C}-$ & $\mathrm{P}$-value \\
\hline Number of cases & 17 & 23 & 13 & 18 & \\
\hline \multicolumn{6}{|c|}{ Pathological features } \\
\hline \multicolumn{6}{|c|}{ Gender } \\
\hline Male & 8 & 11 & 5 & 8 & \\
\hline Female & 9 & 12 & 8 & 10 & \\
\hline \multicolumn{6}{|c|}{ Histological differentiation } \\
\hline Well/moderate & 12 & 20 & 12 & 17 & n.s \\
\hline Poor/mucinous & 5 & 3 & 1 & 1 & \\
\hline \multicolumn{6}{|c|}{ Lymph node metastasis } \\
\hline Negative & 4 & 19 & 12 & 17 & $\begin{array}{c}(\mathrm{N}+\mathrm{C}-\mathrm{vs} . \mathrm{N}+\mathrm{C}-) \\
(\mathrm{N}+\mathrm{C}-\mathrm{vs} . \mathrm{N}-\mathrm{C}+) \\
(\mathrm{N}+\mathrm{C}-\mathrm{vs} . \mathrm{N}-\mathrm{C}-) \\
(\mathrm{p}<0.01)\end{array}$ \\
\hline Positive & 13 & 4 & 2 & 1 & \\
\hline \multicolumn{6}{|c|}{ Lymphatic invasion } \\
\hline Negative & 0 & 2 & 1 & 1 & n.s \\
\hline Positive & 17 & 21 & 12 & 17 & \\
\hline \multicolumn{6}{|l|}{ Venous invasion } \\
\hline Negative & 1 & 0 & 1 & 1 & n.s \\
\hline Positive & 16 & 23 & 12 & 17 & \\
\hline
\end{tabular}

$\mathrm{N}+\mathrm{C}+$, positive nuclear Aurora B and positive cytoplasmic Survivin expression; N+C-, positive nuclear Aurora B and negative cytoplasmic Survivin expression; N-C+, negative nuclear Aurora B and positive cytoplasmic Survivin expression; N-C-, negative nuclear Aurora B and negative cytoplasmic Survivin expression; n.s., not significant.

Table IV. Correlation between the expression of Aurora B/ Survivin and primary tumor/ metastatic lymph nodes.

\begin{tabular}{|c|c|c|c|c|c|c|c|c|c|}
\hline & \multicolumn{2}{|c|}{ Aur B N } & \multirow{2}{*}{$\mathrm{P}$-value } & \multicolumn{2}{|c|}{ Sur N } & \multirow{2}{*}{ P-value } & \multicolumn{2}{|c|}{ Sur C } & \multirow{2}{*}{ P-value } \\
\hline & + & - & & + & - & & + & - & \\
\hline Primary tumor & 38 & 27 & $<0.01$ & 48 & 17 & $<0.01$ & 27 & 38 & $<0.01$ \\
\hline Metastatic lymph node & 13 & 1 & & 1 & 13 & & 12 & 2 & \\
\hline
\end{tabular}

Sur C, cytoplasmic Survivin expression; Sur N, nuclear Survivin expression; Aur B N, nuclear Aurora B expression.

and positive nuclear Aurora B expression was significantly correlated with lymph node metastasis $(\mathrm{P}<0.001$ and $\mathrm{P}<0.05$, respectively), compared with positive cytoplasmic Survivin and negative nuclear Aurora B expression, and negative cytoplasmic Survivin and negative nuclear Aurora B expression, respectively (Table III). Both nuclear Aurora B and cytoplasmic Survivin cases revealed $76 \%$ lymph node metastasis.

Aurora $B$ and Survivin expression and pathological factors in primary colorectal tumors and lymph node metastasis. The varying expression of Aurora B and Survivin in primary colorectal tumors and lymph node metastasis was examined.
Metastatic cases were found to exhibit a higher frequency of nuclear Aurora B and cytoplasmic Survivin expression, and a lower frequency of nuclear Survivin expression than primary tumor cases (Fig. 1C-g and h, and Table IV).

\section{Discussion}

In the present study, we examined the expression of Aurora B and Survivin in 20 normal colonic mucosa and 65 colorectal carcinoma samples by immunohistochemistry. The results showed that nuclear Aurora B, and nuclear and cytoplasmic Survivin were highly and frequently expressed in colorectal 
carcinoma cells. Moreover, the overexpression of nuclear Aurora B and cytoplasmic Survivin was significantly correlated with lymph node metastasis.

Aurora B kinase is a chromosomal passenger protein and it is essential for chromosome segregation through the phosphorylation of mitotic histone H3 $(1,2)$. The phosphorylation status of histone H3 may be balanced by Aurora B kinase activity and PPI phosphatase activity (9). Overexpression of Aurora B produces multinuclearity and increases ploidy, which is important during human cancer development $(2,10)$. In this study, we examined the expression of Aurora B in colorectal carcinoma. Aurora B expression levels were significantly higher in colorectal carcinoma than in normal colonic mucosa, and a high nuclear Aurora B expression was associated with lymph node metastasis. We previously identified that nuclear Aurora B expression is correlated with cell proliferation, multinuclearity and metastasis in oral cancer (6). Aurora B expression is also associated with a poor prognosis in prostate (4), endometrial (3) and thyroid carcinoma (5). Aurora B is also responsible for oncogenic Ras-mediated cell transformation, leading to the accelerated proliferation of tumor cells (11). These findings of these reports therefore confirm the findings of the present study. The detailed mechanism of metastasis promoted by Aurora B overexpression remains to be elucidated. Therefore, the correlation between Aurora B overexpression and migration or invasion of colorectal carcinoma cells should be investigated.

Survivin is a bifunctional protein that suppresses apoptosis and regulates cell division $(12,13)$. Nuclear Survivin is suspected to control cell division, whereas cytoplasmic Survivin is considered to be cytoprotective (14). Survivin has a nuclear export signal (NES) in the linker region between the BIR domain and the $\mathrm{COOH}$-terminal $\alpha$ helix (14-16). Results of certain studies have shown the nuclear translocation and accumulation of cytoplasmic Survivin following treatment with leptomycin B $(15,16)$. In our study, cytoplasmic Survivin was associated with lymph node metastasis. Cytoplasmic Survivin is characterized as anti-apoptotic and is associated with microtubules, directly or indirectly interfering with the function of caspases (8). Our result is also supported by observations that the cytoplasmic expression of Survivin is associated with a poor outcome in breast cancer (17), lymphoma (18), liver cancer (19) and gastric carcinoma (20). In our previous study, the cytoplasmic Survivin overexpression was found to be associated with a poor prognosis in colorectal carcinoma (21).

Previous studies have shown that Survivin acts as a subunit of the chromosomal passenger complex (CPC) and interacts with other subunits of the CPC such as Aurora B, INCENP and Borealin to regulate cell division $(12,13)$. We have found that the nuclear Survivin expression is significantly correlated with Ki-67 and Aurora B expression in oral squamous cell carcinoma (OSCC) (22). Notably, OSCC cases with nuclear Survivin and Aurora B expression exhibited marked malignant behavior. However, in this study, nuclear Survivin was not associated with Aurora B and pathological factors in colorectal carcinoma. The frequency of Survivin expression was extremely high in colorectal carcinomas compared with OSCC cases, thus nuclear Survivin may have varying roles in epithelial cancer and adenocarcinoma.

In this study, we found that the overexpression of nuclear Aurora B and cytoplasmic Survivin was significantly correlated with lymph node metastasis. Moreover, both nuclear Aurora B and cytoplasmic Survivin cases showed far poorer prognosis in colorectal carcinomas. Thus, nuclear Aurora B and cytoplasmic Survivin may be strong markers for the prediction of the malignancy of colorectal carcinomas.

In conclusion, our present findings showed that nuclear Aurora B and cytoplasmic Survivin expression are involved in lymph node metastasis, and both nuclear Aurora B and cytoplasmic Survivin are strongly associated with lymph node metastasis in colorectal cancer.

Therefore, we suggest that nuclear Aurora B and cytoplasmic Survivin are useful diagnostic markers and therapeutic targets in colorectal carcinoma.

\section{Acknowledgements}

We thank Mr. H. Ishitake, K. Matumura and T. Nagata of Hiroshima Memorial Hospital for providing tissues and technical assistance.

\section{References}

1. Adams RR, Carmena M and Earnshaw WC: Chromosomal passengers and the (aurora) ABCs of mitosis. Trends Cell Biol 11: 49-54, 2001.

2. Tatsuka M, Katayama H, Ota T, Tanaka T, Odashima S, Suzuki F and Terada Y: Multinuclearity and increased ploidy caused by overexpression of the Aurora B and Ipl1-like midbody-associated protein mitotic kinase in human cancer cells. Cancer Res 58: 4811-4816, 1998

3. Kurai M, Shiozawa T and Shih HC: Expression of Aurora kinases A and B in normal, hyperplastic, and malignant human endometrium: Aurora B as a predictor for poor prognosis in endometrial carcinoma. Hum Pathol 36: 1281-1288, 2005.

4. Lee EC, Frolov A, Li R, Ayala G and Greenberg NM: Targeting Aurora kinases for the treatment of prostate cancer. Cancer Res 66: 4996-5002, 2001.

5. Sorrentino R, Libertini S, Pallante PL, Troncone G, Palombini L, Bavetsias V, Spalletti-Cernia D, Laccetti P, Linardopoulos S, Chieffi P, Fusco A and Portella G: Aurora B overexpression associates with the thyroid carcinoma undifferentiated phenotype and is required for thyroid carcinoma cell proliferation. J Clin Endocrinol Metab 90: 928-935, 2005.

6. Qi G, Ogawa I, Kudo Y, Miyauchi M, Siriwardena BSMS, Shimamoto F, Tatsuka M and Takata T: Aurora-B expression and its correlation with cell proliferation and metastasis in oral cancer. Virchows Arch 450: 297-302, 2007.

7. Ambrosini G, Adida C and Altieri DC: A novel anti-apoptosis gene, Survivin, expressed in cancer and lymphoma. Nat Med 3: 917-921, 1997.

8. Chiou SK, Jones MK and Tarnawski AS: Survivin an antiapoptosis protein: its biological roles and implications for cancer and beyond. Med Sci Monit 9: 125-129, 2003.

9. Hsu JY, Sun ZW, Li X, Reuben M, Tatchell K, Bishop DK, Grushcow JM, Brame CJ, Caldwell JA, Hunt DF, Lin R, Smith MM and Allis CD: Mitotic phosphorylation of histone H3 is governed by Ipl1/aurora kinase and Glc7/PP1 phosphatase in budding yeast and nematodes. Cell 102: 279-291, 2000.

10. Ota T, Suto S, Katayama H, Han ZB, Suzuki F, Maeda M, Tanino M, Terada $\mathrm{Y}$ and Tatsuka M: Increased mitotic phosphorylation of histone $\mathrm{H} 3$ attributable to AIM-1/Aurora B overexpression contributes to chromosome number instability. Cancer Res 62: 5168-5177, 2002.

11. Kanda A, Kawai H, Suto S, Kitajima S, Sato S, Takata T and Tatsuka M: Aurora-B/AIM-1 kinase activity is involved in Rasmediated cell transformation. Oncogene 24: 7266-7272, 2006.

12. Honda R, Korner R and Nigg EA: Exploring the functional interactions between Aurora B, INCENP, and Survivin in mitosis. Mol Biol Cell 14: 3325-3341, 2003.

13. Beardmore VA, Ahonen LJ, Gorbsky GJ and Kallio MJ: Survivin dynamics increases at centromeres during $\mathrm{G} 2 / \mathrm{M}$ phase transition and is regulated by microtubule-attachment and Aurora B kinase activity. J Cell Sci 117: 4033-4042, 2004. 
14. Stauber RH, Mann W and Knauer SK: Nuclear and cytoplasmic Survivin: Molecular mechanism, prognostic, and therapeutic potential. Cancer Res 67: 5999-6002, 2007.

15. Knauer SK, Bier C, Habtemichael N and Stauber RH: The Survivin-Crm1 interaction is essential for chromosomal passenger complex localization and function. EMBO Rep 7: 1259-1265, 2006.

16. Colnaghi R, Connell CM, Barrett RM and Wheatley SP Separating the anti-apoptotic and mitotic roles of survivin. J Biol Chem 281: 33450-33456, 2006.

17. Tanaka K, Iwamoto S, Gon G, Nohara T, Iwamoto $M$ and Tanigawa N: Expression of Survivin and its relationship to loss of apoptosis in breast carcinomas. Clin Cancer Res 6: 127-134, 2000

18. Adida C, Haioun C, Gaulard P, et al: Prognostic significance of Survivin expression in diffuse large B-cell lymphomas. Blood 96: 1921-1925, 2000.
19. Ikeguchi M, Ueta T, Yamane Y, Hirooka Y and Kaibara N: Inducible nitric oxide synthase and Survivin messenger RNA expression in hepatocellular carcinoma. Clin Cancer Res 8: 3131-3136, 2002

20. Wakana Y, Kasuya K, Katayanagi S, et al: Effect of surviving on cell proliferation and apoptosis in gastric cancer. Oncol Rep 9: 1213-1218, 2002

21. Qi G, Tuncel H, Aoki E, Tanaka S, Oka S, Kaneko I, Okamoto M, Tatsuka M, Nakai S and Shimamoto F: Intracellular localization of survivin determines biological behavior in colorectal cancer. Oncol Rep 22: 557-562, 2009.

22. Qi G, Kudo Y, Ando T, Siriwardena BSMS, Yoshida M, Keikahee MR, Ogawa I and Takata T: Nuclear Survivin expression is correlated with malignant behaviors of head and neck cancer together with Aurora-B. Oral Oncol 46: 263-270, 2010. 